https://doi.org/10.1590/198053146641

\title{
PAIS PROFESSORES HOMENS E O ACOMPANHAMENTO DA VIDA ESCOLAR DOS FILHOS
}

\author{
Rosilane Katia de Oliveira' \\ Marlice de Oliveira e Nogueira"
}

\section{Resumo}

0 artigo discute as práticas educativas desenvolvidas na escolarização dos filhos por dez pais professores homens, residentes em cinco cidades do estado de Minas Gerais. Primeiramente, realizamos um levantamento na Superintendência Regional de Ensino de Ouro Preto, objetivando identificar o número de professores/as em atuação na educação básica e, posteriormente, procedemos à escolha dos sujeitos. Em seguida, aplicamos um questionário aos pais professores para traçar o perfil sociológico, profissional e educacional e entrevistas semiestruturadas que tiveram como foco as dinâmicas e práticas educativas familiares. Os resultados indicam que os pais professores homens, com uma carga horária de trabalho docente extensa, monitoram a vida escolar dos filhos, sem, no entanto, exercer forte regulação e controle das atividades escolares e extraescolares, e se mantêm, muitas vezes, nos bastidores do processo de acompanhamento familiar da escolarização.

\section{PAIS PROFESSORES • PRÁTICAS EDUCATIVAS • FILHOS • ESCOLARIZAÇÃO}

\section{MALE TEACHERS WHO ARE FATHERS AND THE MONITORING OF CHILDREN'S SCHOOL LIFE}

\section{Abstract}

The article discusses the educational practices developed regarding children's schooling by ten male teachers, who are fathers, living in five cities in the state of Minas Gerais. First, we conducted a survey at the Regional Teaching Superintendence of Ouro Preto aiming to identify the number of teachers working in basic education, and then, we proceeded to the choice of subjects. Next, the male teachers, who are fathers, answered a questionnaire to assess their sociological, professional and educational profile and we conducted semi-structured interviews focused on family educational dynamics and practices. The results indicate that male teachers, who are also fathers, with an extensive teaching workload, play a role in monitoring their children's school life. However, they do not exercise strong regulation and control of school and extra school activities, and often remain behind the scenes in the process of family schooling monitoring.

\section{FATHERS TEACHERS • EDUCATIONAL PRACTICE • CHILD • SCHOOLING}

I Universidade Federal de Ouro Preto (Ufop), Ouro Preto (MG), Brasil; http://orcid.org/0000-0003-2076-5783; rosilanekatia@yahoo.com.br

II Universidade Federal de Ouro Preto (Ufop), Ouro Preto (MG), Brasil; https://orcid.org/0000-0002-6295-5473; nogueira_mar@uol.com.br 


\section{PÈRES ENSEIGNANTS ET LE SUIVI DE LA VIE SCOLAIRE DE LEURS ENFANTS}

\section{Résumé}

Cet article analyse des pratiques éducatives mises en oeuvre par dix pères enseignants résidant dans cinq villes de l'État de Minas Gerais, concernant la scolarisation de leurs enfants. Nous avons d'abord rélèvé à la Superintendência Regional de Ensino de Ouro Preto [Direction Régionale de l'Enseignement de la ville d'Ouro Preto] le nombre d'enseignantes dans l'enseignement primaire et au collège et ensuite nous avons choisi les participants. Nous avons soumis un questionnaire aux pères enseignants pour établir leur profil sociologique, professionnel et éducatif et réalisé des entrevues semi-structurées axées sur la dynamique et les pratiques éducatives familiales. Les résultats indiquent que les pères enseignants, ayant une charge importante de travail, accompagnent la vie scolaire de leurs enfants sans toutefois exercer un fort contrôle sur leurs activités scolaires et extrascolaires et qu'ils demeurent le plus souvent dans les coulisses du processus de suivi familial de la scolarité.

\section{PÈRES ENSEIGNANTS • PRATIQUES ÉDUCATIVES • ENFANTS • SCOLARISATION}

\section{PADRES PROFESORES HOMBRES Y EL SEGUIMIENTO DE LA VIDA ESCOLAR DE LOS HIJOS}

\section{Resumen}

El artículo analiza las prácticas educativas desarrolladas en la escolarización de los hijos por parte de diez padres maestros, que residen en cinco ciudades del estado de Minas Gerais. Primero, realizamos una encuesta en la Superintendencia Regional de Enseñanza en Ouro Preto, con el objetivo de identificar el número de maestros que trabajan en educación básica y, posteriormente, elegimos a las personas. Luego, aplicamos un cuestionario a los padres profesores para elaborar el perfil sociológico, profesional y educativo y entrevistas semiestructuradas que se centraron en la dinámica y prácticas educativas familiares. Los resultados indican que los padres profesores hombres, con una gran carga de trabajo docente, monitorean la vida escolar de sus hijos sin, no obstante, ejercer una fuerte regulación y control de las actividades escolares y extraescolares, y a menudo permanecen en segundo plano en el proceso de seguimiento familiar de la escolarización.

PADRES PROFESORES • PRÁCTICAS EDUCATIVAS • HIJOS • ESCOLARIZACIÓN 
em 2018, que se insere nos estudos da Sociologia da Educação, em particular, na interface da relação família-escola. A pesquisa investigou as práticas educativas familiares de dez pais professores homens da educação básica em cinco cidades do estado de Minas Gerais: ${ }^{1}$ Mariana, Acaiaca, Diogo de Vasconcelos, Ouro Preto e Itabirito.

A partir de uma revisão da literatura sobre as práticas educativas de pais professores da educação básica, verificamos que são raras as pesquisas que se propuseram a investigar pais professores, principalmente quando nos referimos aos progenitores masculinos. No Brasil, localizamos uma tese e três dissertações (SANTANA, 2005; ANDRADE, 2006; REIS, 2006; NOGUEIRA, 2011) e quatro artigos derivados dessas pesquisas publicadas em periódicos e anais de eventos (SILVA, 2002; NOGUEIRA, 2013; NOGUEIRA, 2015; NOGUEIRA; NOGUEIRA, 2017). Internacionalmente, na França e em Portugal, destacamos os trabalhos de Silva (2003), Vieira e Relvas (2005), Barg (2011) e Lasne (2012).

Esses estudos supracitados demonstram efeitos positivos do exercício da profissão docente pelos pais na vida escolar dos filhos/as. Porém, essas pesquisas 
continham em suas amostras um número bastante reduzido de pais professores do sexo masculino em relação ao número de mulheres. Além disso, é necessário destacar que somente a pesquisa de doutoramento de Nogueira (2011) investigou de modo mais amplo e aprofundado o interior das famílias de pais professores. Conforme indica Nogueira (2011), devido ao número pequeno de pais professores participantes de sua investigação (13 homens em um universo de 40 docentes pesquisados), a compreensão acerca das práticas educativas dos progenitores masculinos ainda apresenta lacunas. Nesse contexto, propusemos, como objetivo principal do estudo, investigar os efeitos de ser pai professor do sexo masculino atuante na educação básica na vida familiar e na escolarização dos filhos.

De abordagem qualitativa, a pesquisa compreendeu dois momentos. $\mathrm{Na}$ fase inicial, realizamos um levantamento no banco de dados da Superintendência Regional de Ensino de Ouro Preto (25 SRE), objetivando levantar o número de professores/as em exercício na educação básica nos cinco municípios investigados, em especial os professores homens. Em seguida, procedemos à seleção dos sujeitos mediante os seguintes critérios: possuir diploma de ensino superior; ser pai professor residente em uma das cinco cidades investigadas; ser pai professor em exercício na rede escolar pública (municipal ou estadual); ter filhos frequentando a educação básica e sob sua tutela e, em casos em que o pai professor fosse casado, preferencialmente, a esposa deveria exercer outra função diferente da docência.

No segundo momento, após a aplicação dos critérios e a composição de uma amostra de dez pais professores, utilizamos como instrumentos para a coleta de dados: um questionário com questões abertas e fechadas que objetivou traçar o perfil sociológico, profissional e educacional desses pais professores homens; e entrevistas semiestruturadas que tiveram como foco as dinâmicas familiares e as práticas educativas desenvolvidas por eles no quadro da vida escolar dos filhos.

Nesse enredo, para analisar qualitativamente as práticas educativas e estratégias ${ }^{2}$ de escolarização desenvolvidas pelos pais professores homens no âmbito da escolarização dos filhos/as, elencamos, a partir da articulação da teoria que fundamenta o estudo e dos dados coletados por meio das entrevistas, cinco eixos que se desdobraram em categorias de análise: 1) dinâmica interna familiar; 2) práticas educativas e estratégias de escolarização; 3) uso do tempo livre - atividades extraescolares e de lazer; 4) práticas familiares de leitura; e 5) relação entre a vida profissional e familiar. No primeiro eixo, utilizamos três categorias de análise: 1) organização da vida familiar; 2) divisão das tarefas domésticas; e 3) relações de autoridade e valores transmitidos aos filhos. No segundo eixo, cinco categorias foram levantadas: 1) escolha do estabelecimento de ensino; 2) modalidades de ajuda pedagógica no quadro da vida escolar dos filhos; 3) relação com a escola e 
com os professores dos filhos; 4) desempenho escolar da prole; e 5) projetos de futuro para os filhos.

No terceiro eixo de análise, tivemos as categorias: 1) atividades extraescolares; e 2) atividades de lazer da família. Duas categorias compuseram o quarto eixo: 1) práticas de leitura familiares dos pais e filhos; e 2) frequência em atividades culturais diversas. Por fim, o quinto eixo de análise discutiu: 1) vida profissional e familiar; e 2) percepção da condição híbrida de pai e professor.

O texto que se segue está organizado em três partes, sendo que a primeira apresenta o perfil sociológico dos pais professores investigados, a segunda aborda as dinâmicas familiares e a terceira discute as práticas educativas e de escolarização desenvolvidas pelos pais professores homens na vida escolar dos filhos.

\section{PERFIL SOCIOLÓGICO DOS PAIS PROFESSORES}

A partir de dados obtidos por meio de questionário, foi possível traçar um perfil sociológico, profissional e educacional dos pais professores:

\section{QUADRO 1}

PERFIL DOS PAIS PROFESSORES

\begin{tabular}{|c|c|c|c|c|c|c|}
\hline $\begin{array}{c}\text { PAIS } \\
\text { PROFESSORES }\end{array}$ & IDADE & $\begin{array}{c}\text { CIDADE } \\
\text { ONDE RESIDE }\end{array}$ & $\begin{array}{c}\text { GRAU DE } \\
\text { ESCOLARIDADE } \\
\text { DO CÔNJUGE }\end{array}$ & $\begin{array}{l}\text { OCUPAÇÃO } \\
\text { DO CÔNJUGE }\end{array}$ & $\begin{array}{l}\text { N. DE } \\
\text { FILHOS }\end{array}$ & FORMAÇÃO \\
\hline Maurício ${ }^{3}$ & 48 & Mariana & Fund. II incompleto & Agricultora & 5 & $\begin{array}{l}\text { Lic. Educação } \\
\text { Básica }\end{array}$ \\
\hline José & 42 & Acaiaca & Superior completo & Professora & 2 & $\begin{array}{l}\text { Lic. Educação } \\
\text { Básica }\end{array}$ \\
\hline Henrique & 45 & Mariana & Fund. II completo & $\begin{array}{l}\text { Secretária } \\
\text { escolar }\end{array}$ & 2 & $\begin{array}{l}\text { Lic. Educação } \\
\text { Básica }\end{array}$ \\
\hline Marcos & 39 & $\begin{array}{l}\text { Diogo de } \\
\text { Vasconcelos }\end{array}$ & Superior Incompleto & $\begin{array}{l}\text { Auxiliar } \\
\text { administrativo }\end{array}$ & 1 & $\begin{array}{l}\text { Lic. Educação } \\
\text { Básica }\end{array}$ \\
\hline João & 38 & Ouro Preto & Médio completo & Do lar & 2 & Geografia \\
\hline Paulo & 53 & Itabirito & Superior completo & $\begin{array}{l}\text { Atendente de } \\
\text { telefone }\end{array}$ & 2 & História \\
\hline Sandro & 36 & Mariana & Superior completo & Professora & 1 & $\begin{array}{l}\text { Educação } \\
\text { física }\end{array}$ \\
\hline Pedro & 35 & Mariana & Médio completo & Cabelereira & 1 & $\begin{array}{l}\text { Letras - inglês } \\
\text { Matemática }\end{array}$ \\
\hline Jerônimo & 48 & Ouro Preto & Médio completo & Comerciante & 2 & Matemática \\
\hline Vicente & 56 & Ouro Preto & Médio completo & $\begin{array}{l}\text { Atendente em } \\
\text { comércio }\end{array}$ & 2 & \\
\hline
\end{tabular}

Fonte: Elaboração das autoras com base nos dados obtidos por meio do questionário.

Observamos no Quadro 1 que a idade dos pais professores variava de 35 a 56 anos. Essa variação etária também foi encontrada em um estudo exploratório realizado pelo Instituto Nacional de Estudos e Pesquisas Educacionais Anísio Teixeira(Inep)(BRASIL, 2009) em que se verificou que a maioria dos/as professores/as 
brasileiros (68\%) tinham mais de 33 anos de idade. Em referência à modalidade de arranjo familiar, nove pais professores homens eram casados e um declarou ter união estável, sendo, então, a amostra constituída predominantemente por famílias biparentais.

Em relação ao número de filhos, percebemos que, de modo geral, tratava-se de famílias pouco numerosas, com exceção de um caso em que o pai professor tinha cinco filhos. Observamos que o controle da fecundidade percebido nas famílias dos pais professores é um fenômeno presente nas famílias brasileiras, como demonstraram Goldani (1994) e também uma pesquisa mais recente realizada pelo Instituto Brasileiro de Geografia e Estatística (IBGE) (2016). Conforme Bourdieu (2008), reduzir a prole é uma estratégia bastante rentável em famílias de camadas médias, pois possibilita que os pais possam investir mais na escolarização de cada filho/a.

No que diz respeito à família de procriação, notamos, no Quadro 1, que sete pais professores eram casados com esposas menos escolarizadas, somente em dois casos os cônjuges exerciam profissão homóloga à dos pais professores investigados (professora) e as demais exerciam atividades manuais ou tinham ocupações menos qualificadas.

No que concerne aos dados referentes às famílias de origem dos pais professores, identificamos que eles tiveram uma mobilidade social ascendente, tendo em vista o grau de escolaridade dos seus pais (ensino fundamental I completo ou incompleto/analfabeto/a) e a ocupação desses progenitores (pedreiro, carpinteiro, lavrador rural - profissão exercida pelos pais, e dona de casa, doméstica, lavradora, costureira - ocupação principal das mães).

Quanto ao local de moradia dos pais professores, dos três pais que moravam em Ouro Preto, um deles tinha residência em um distrito distante da sede; e dos quatro que moravam em Mariana, dois viviam em distritos também distantes da cidade.

Em relação ao campo de atuação profissional, todos os docentes trabalhavam apenas na rede pública de ensino, sendo que cinco pais professores estavam na rede estadual e cinco na rede municipal de ensino. No que tange ao número de escolas em que trabalhavam os pais professores, cinco relataram possuir outro cargo de docência em outra escola e um declarou exercer a função de coordenador em outra instituição que oferece somente o tempo integral. Ressalta-se também que dois pais professores tinham, na época da pesquisa, outra função diferente da docência (motorista de transporte escolar). E, quanto à carga horária semanal de trabalho dos pais professores, identificamos que oscilava de 16 a 54 horas semanais.

Em referência aos níveis de ensino em que trabalhavam profissionalmente os pais professores, temos: educação infantil (pai professor Maurício); anos iniciais do ensino fundamental (pais professores José, Henrique e Marcos); anos finais do ensino fundamental (pais professores Sandro, João e Paulo); ensino médio (pais professores Vicente, Jerônimo e Pedro). Quanto ao tempo de exercício na profissão docente, os pais professores declararam estar na docência há mais de 
10 anos, compreendidos nos intervalos de: 25 anos ou mais (Paulo e Jerônimo); 20 a 25 anos (Maurício, José e Marcos); 15 a 20 anos (Henrique e Sandro); 10 a 15 anos (João, Pedro e Vicente).

No que se refere ao perfil socioeconômico das famílias investigadas, quanto à posse de bens duráveis, todos os pais professores afirmaram ter computador em casa, nove tinham internet banda larga, três tinham TV paga, e um pai professor declarou que tinha empregada doméstica que trabalhava todos os dias em seu lar. Sobre o número de automóveis, apenas em uma família a posse desse bem não foi relatada. Destaca-se também que, em quatro casos, as famílias relataram possuir dois automóveis. Em relação ao número de casas que os pais professores possuíam, além da residência própria, dois pais professores residentes na zona urbana declararam possuir outro imóvel próprio, situado na zona rural.

Sobre a renda familiar, um deles - pai professor Pedro - declarou ter renda situada na faixa de dois a quatro salários mínimos (R $1.874,00$ a R\$ 3.748,00); ${ }^{4}$ o pai professor Maurício tinha renda entre quatro a dez salários mínimos (R\$ 3.748,00 a R\$ 9.370,00); seis pais professores ( Henrique, Marcos, João, Paulo, Sandro e Vicente) declararam ter uma renda que variava de quatro a seis salários mínimos (R\$ 3.748,00 a R\$ 5.622,00); e José e Jerônimo tinham renda na faixa de seis a oito salários mínimos (R\$ 5.622,00 a R\$ 7.496,00). Esses dados nos permitem situar, mesmo que hipoteticamente, as famílias em diferentes estratos das camadas médias brasileiras (B1, B2, C1 e C2), segundo o Critério de Classificação Econômica Brasil (ASSOCIAÇÃO BRASILEIRA DE EMPRESA DE PESQUISA - ABEP, 2016).

No tocante aos dados da trajetória educacional dos pais professores, sete dos dez pais professores cursaram toda a educação básica em escolas públicas municipais e/ou estaduais, e três deles, embora tenham frequentado grande parte do percurso escolar em instituições públicas, tiveram experiências em escolas básicas da rede particular. Sobre a formação em nível superior, quatro pais professores cursaram a etapa na rede privada de ensino, na modalidade presencial; seis cursaram na rede pública federal, sendo que, desses, três estudaram na modalidade a distância. Em referência à pós-graduação, oito pais professores fizeram cursos de especialização, sendo que quatro deles estudaram em instituições privadas e quatro em instituições públicas.

Diante do exposto, tendo em vista o perfil dos pais professores investigados apresentados, quais os efeitos de ser pai professor homem na vida familiar e quais práticas educativas eles desenvolvem no quadro da vida escolar dos seus filhos?

\section{DINÂMICAS INTERNAS DAS FAMÍLIAS}

Para compreendermos o acompanhamento parental dos pais professores homens na vida escolar de seus filhos/as e as estratégias desenvolvidas no processo de 
escolarização, é essencial que conheçamos alguns aspectos referentes à dinâmica interna das famílias investigadas.

Sobre os modos de funcionamento interno das famílias, os dados revelaram que a presença física dos pais professores em seus lares era bastante reduzida, devido à extensa jornada de trabalho a que estavam submetidos. De acordo com os depoimentos, seis pais professores trabalhavam em mais de uma escola e dois deles possuíam mais de um cargo no serviço público, sendo um dos cargos diferentes da docência. Nesses termos, essa sobrecarga de trabalho obrigava os pais professores a ficarem em casa somente à tarde ou à noite, a não ser em sua folga semanal e nos finais de semana, em que tinham mais tempo para a permanência no lar. Os outros dois pais professores trabalhavam somente em um turno (manhã), mas relataram que essa situação era novidade, pois, anteriormente, trabalhavam com uma extensa carga horária de trabalho.

Em relação às mães, a partir dos depoimentos, notou-se que não existe uma homogeneidade no tocante à presença materna cotidiana no ambiente familiar, mas, de modo geral, as mães permaneciam mais tempo no lar do que os pais. Os cônjuges dos pais professores Marcos e José trabalhavam durante todo o dia, e estavam presentes em casa somente à noite e nos finais de semana. As esposas dos pais professores Maurício, Pedro e João passavam bastante tempo em casa, pois as atividades laborais que exerciam eram realizadas dentro do próprio domicílio. Outras três mães, casadas com os pais professores Jerônimo, Sandro e Henrique, trabalham somente uma parte do dia, ou de manhã ou à tarde. E, em relação às esposas de Vicente e Paulo, a do primeiro exercia ocupação de atendente de lanchonete, com horários de trabalho alternados (dia sim, dia não), e a esposa de Paulo trabalhava diariamente até por volta das 14h30, permanecendo em casa durante o restante do dia.

Ainda nesse contexto de investigação, outro aspecto discutido sobre o modo de funcionamento interno das famílias dos pais professores refere-se à terceirização do cuidado com os filhos na ausência dos pais. Os resultados indicaram que, nos casos em que isso acontecia, os pais professores recorriam, de modo geral, à família extensiva, contando com o auxílio de parentes, como, por exemplo, os avós paternos ou maternos, a tia dos filhos ou a sogra. ${ }^{5}$ Embora essas situações tenham sido apontadas pelos pais professores como de pouca frequência, pois em muitos casos eram as mães que cuidavam dos filhos/as, os dados mostram que o apelo à família extensiva para o auxílio no cuidado com os filhos era um recurso comumente utilizado pela maioria dos pais entrevistados.

No que diz respeito à divisão das tarefas domésticas no interior das famílias, os resultados evidenciaram que, em algumas famílias, podemos observar a permanência de uma tradicional divisão sexual do trabalho doméstico, na qual as mães é que ficam mais encarregadas por esse trabalho, sendo que os pais,

5 Ressalta-se que, em três famílias (Maurício, João e Pedro), o recurso de apelo aos familiares ou a outras pessoas para o cuidado com os filhos não era comumente utilizado. No primeiro caso, devido à maior presença da mãe no ambiente familiar, e, no caso das outras duas famílias, em função da distância geográfica entre os locais de moradia da família estendida e a dos pais professores. 
em algumas vezes, oferecem alguns auxílios, ou seja, os pais professores assumem um papel de “colaboradores” (MARTINS; LUZ; CARVALHO, 2010). Conforme Singly (2007), as mulheres ainda têm assumido fortemente os afazeres domésticos em relação aos homens, prevalecendo, assim, uma divisão desigual dessas tarefas entre os cônjuges, notável tanto em famílias em que as mulheres são exclusivamente donas de casa quanto nas famílias em que as mulheres exercem dupla jornada de trabalho.

No tocante à tarefa de acompanhamento da escolarização dos filhos, observamos que, nas famílias dos pais professores Jerônimo, Sandro, João e Maurício, as tarefas pareciam ser divididas entre os cônjuges. Segundo o pai professor Jerônimo, nessa divisão, ele auxiliava mais a filha que frequentava o ensino médio em suas atividades escolares não apenas pelo fato de ser professor mas também porque a esposa se dedicava a ajudar o filho mais novo, que cursava o $3^{\circ}$ ano do ensino fundamental. Esse contexto também é semelhante ao da família de João, em que o pai acompanhava seu filho nos estudos dos anos finais do ensino fundamental, e a esposa orientava o filho que frequentava a educação infantil.

Na família do pai professor Henrique, esse acompanhamento centrava-se mais na figura da mãe, devido à carga horária de trabalho extensiva do pai. Nas famílias de José e Paulo, os filhos eram autônomos para desenvolverem suas atividades escolares, sendo que, em casos de dificuldades, eles recorriam tanto ao pai quanto à mãe. Já na família do pai professor Vicente, o pai relatou que a filha pedia pouca ajuda a ele, ou seja, parece que a filha também era autônoma para resolver suas tarefas. Porém, ele ressaltou: “O que eu puder ajudar eu ajudo”.

Identificamos também que, em uma única família, a do pai professor Pedro, essa responsabilidade do acompanhamento da escolarização da filha era cumprida exclusivamente pelo pai professor. Segundo o entrevistado, isso pode estar ligado ao fato de ele ser professor e a mãe não possuir o diploma de ensino superior. Esse dado corrobora os resultados encontrados na pesquisa de Nogueira (2011). Segundo a pesquisadora, nos casos em que o pai era professor e a mãe exercia outra função diferente da docência, o acompanhamento na escolarização dos filhos ficava sob a responsabilidade do pai professor devido à sua ocupação como docente. Nessa senda, percebemos que, nos demais casos, em que as esposas não tinham formação em nível superior, elas dividiam essa tarefa do acompanhamento na escolarização dos filhos com os maridos, dados que destoam dos resultados encontrados por Nogueira (2011), que constatou que essa divisão havia sido notada quando o pai e a mãe exerciam o cargo de docentes. No entanto, os dados ainda indicaram que, mesmo que se possa evidenciar certo protagonismo das mães no acompanhamento escolar, ou uma divisão mais equilibrada dessas tarefas, nos casos em que a ajuda às atividades escolares dos filhos exigia a posse de um maior conhecimento científico/escolar, o fato de ser professor influenciava na divisão da tarefa de acompanhamento da escolarização dos filhos. 


\section{AS PRÁTICAS EDUCATIVAS E DE ESCOLARIZAÇÃO}

Para analisarmos as estratégias de escolarização desenvolvidas pelos pais professores no âmbito da escolarização dos filhos/as, procuramos identificar o tipo de estabelecimento de ensino que a prole cursava, as dimensões do acompanhamento pedagógico e as formas de intervenção dos pais nas escolas dos filhos.

A partir dos anos 1980, a escolha do estabelecimento de ensino tem se tornado objeto de estudos no campo da Sociologia da Educação. Os estudiosos lembram que, nesse período, várias reformas educacionais emergiram em vários países, produzindo uma maior diversificação das redes escolares públicas e privadas, o que possibilitou que os pais ampliassem as chances de escolha no leque das possíveis instituições de ensino para escolarizar os filhos (RESENDE; NOGUEIRA; NOGUEIRA, 2011).

Diante disso, perguntamo-nos: que tipos de estabelecimentos de ensino os pais professores escolhiam para escolarizar seus filhos? Quais os motivos da escolha? Podem eles serem considerados "bons escolhedores"?

Do total de professores investigados, seis "escolheram” a rede pública para escolarizar os filhos, fenômeno dissonante em relação às outras pesquisas sociológicas realizadas com pais professores (REIS, 2006; SANTANA, 2005; NOGUEIRA, 2011). Esses estudos demonstram que a maioria dos pais professores investigados preferiam matricular seus filhos em escolas particulares, o que evidenciava, assim, um descontentamento com a rede pública de ensino. E revelam também que os pais professores que optavam pela escola pública o faziam devido aos imperativos econômicos (NOGUEIRA, 2011; REIS, 2006; SANTANA; 2005). Nogueira (2011) e Nogueira e Nogueira (2017) argumentam que, diante da inevitabilidade de matricular seus filhos na escola pública, os pais professores por elas pesquisados não fizeram essa escolha de maneira aleatória. Desse modo,

\footnotetext{
[...] as famílias elaboram, dentro de seu universo de possíveis, uma classificação objetiva e simbólica de um leque de estabelecimentos, e optam por aquele que melhor atenda a seus objetivos. (NOGUEIRA; NOGUEIRA, 2017, p. 17)
}

Nesse contexto, questiona-se: quais os motivos que levaram os pais professores do presente estudo a matricularem seus filhos tanto nas redes públicas quanto nas privadas? Quais critérios eles levaram em consideração nessa escolha? E por que predominava a escola pública como escolha para a escolarização dos filhos, contrariando a lógica do evitamento da rede pública, fortemente apresentada nos trabalhos de Nogueira (2011), Reis (2006) e Santana (2005)?

A partir dos depoimentos dos pais professores entrevistados, identificamos que quatro pais professores (José, Maurício, Sandro e Marcos) que escolarizavam seus filhos somente na rede pública municipal ou estadual relataram que a escolha da escola dos filhos estava mais relacionada à "falta de opção", devido ao contexto no qual as famílias estão inseridas, pois dois desses pais professores - Marcos e José - residiam em duas cidades pequenas, respectivamente Diogo de 
Vasconcelos e Acaiaca, que por sua vez, tinham um número reduzido de habitantes e de instituições escolares. Esses pais professores também ressaltaram a ausência de escolas particulares nesses dois municípios, evidenciada nos excertos de suas entrevistas. Os outros dois pais professores - Mauricio e Sandro - moravam em área rural, o que também restringia as possibilidades de escolha da escola, tendo em vista as dificuldades geográficas de locomoção. Assim, é possível dizer que esses pais professores não tiveram outra "saída” a não ser matricular seus filhos na única escola que havia na cidade onde residiam ou mais perto do local de sua residência, pois o deslocamento para escolarizar os filhos em outras escolas se tornaria mais difícil e oneroso, tendo em vista suas condições objetivas de existência.

Nessa perspectiva, dado o contexto em que essas famílias estavam inseridas, é possível argumentar que a escolha dos estabelecimentos de ensino para escolarizar os filhos está relacionada a motivos funcionais, ou seja, de "ordem prática” (ANDRADE, 2006), como, por exemplo, a proximidade entre a escola e o local de moradia - dados encontrados também nas pesquisas de Andrade (2006) e Reis (2006).

Outros dois pais professores, João e Vicente, também tinham filhos matriculados em estabelecimentos públicos, sendo que na primeira família havia um deles estudando em uma escola pública situada em outra cidade. Para esses dois pais professores, os trunfos adquiridos pela profissão docente evidenciados também na pesquisa de Nogueira (2011) os auxiliaram, dentro de um leque de possibilidades, a escolher a escola dos filhos. Os trechos das entrevistas também demonstraram que o "capital profissional” (ANDRADE, 2006) advindo da experiência docente foi crucial na escolha da escola para matricular o filho. Desse modo, é possível dizer que o fato de ser professor tem efeitos positivos na escolha das instituições escolares para os filhos, dados que já foram demonstrados em outras pesquisas sociológicas realizadas com pais professores (REIS, 2006; NOGUEIRA, 2011). Além disso, ressalta-se que, na família do pai professor João, a escolha da escola pública para os filhos parecia atrelada aos recursos financeiros, pois o pai professor ciente da "inevitabilidade" (NOGUEIRA, 2011) em matricular os filhos em instituições públicas lança mãos de outras estratégias para compensar e minimizar os possíveis efeitos negativos da formação dos filhos nessas instituições: "a gente optou em colocar ele na escola pública e fazer os investimentos por fora, como o inglês, livros, essas coisas, para ir complementando" (Pai professor João).

Os pais professores Pedro e Henrique tinham filhos matriculados somente na rede privada de ensino. Pedro relatou que o motivo da escolha do estabelecimento de ensino estava ligado ao "medo" da escola pública, devido às informações obtidas sobre o modo de funcionamento das escolas, o qual, certamente, advém da sua experiência profissional na docência. É possível argumentar que o descrédito em relação à escola pública evidenciado no relato desse pai professor é um dos motivos que levaram também a maioria dos pais professores participantes das pesquisas de Santana (2005), Reis (2006) e Nogueira (2011) a não matricularem seus filhos na rede pública de ensino. Assim, podemos inferir que o evitamento 
da rede pública de ensino para a escolarização dos filhos é um comportamento, de modo geral, bastante presente entre os pais professores.

No depoimento do pai professor Henrique, os dados evidenciaram que, embora o pai escolarizasse os filhos na rede particular, quando questionado sobre a escolha da escola particular, tendo em vista que, em sua visão expressa em relato da entrevista, não há diferenças entre escola pública e particular, argumentou-nos que essa escolha foi motivada pelo desejo de sua esposa e que, embora seja ele quem pague as escolas, em sua percepção, seus filhos deveriam estudar na rede pública. Notamos, assim, nesse caso, que matricular os filhos na rede particular de ensino tinha seu pilar na figura da mãe, mas era aceito por ambos, pai e mãe. Dessa forma, podemos também levantar a hipótese de certo efeito de legitimidade (BOURDIEU, 2008) na resposta do pai professor Henrique, que, ao atuar profissionalmente na rede pública de ensino, poderia se sentir constrangido a mencionar os motivos da opção pela escola particular e pelo evitamento da escola pública para os seus filhos.

Ainda nesse quadro de discussão, os dados referentes aos critérios levados a cabo pelos pais professores na escolha da escola particular para os filhos nos causaram surpresa, pois os motivos estavam relacionados às amizades do filho e ou informações de parentes que já haviam estudado na mesma escola. Esses resultados destoam daqueles encontrados nas pesquisas de Nogueira (2011) e Reis (2006). Embora, no estudo de Nogueira (2011), alguns pais professores tenham explicitado critérios de natureza funcional, como a proximidade da escola, a maioria apresentou critérios mais “expressivos”, como qualidade do ensino, a proposta pedagógica, o clima escolar, dentre outros fatores. Podemos inferir, no entanto, que, por falta de dados suficientes para aprofundar essas análises, esses pais professores, acometidos por condições sociais e econômicas menos favoráveis do que as famílias pesquisadas por Nogueira (2011) e submetidos a lógicas profissionais também distintas, tenham suas práticas educativas e estratégias de escolarização afetadas por essas condições. É provável também que tenham menores possibilidades de converter um possível capital de informações privilegiadas sobre a escola e o mundo escolar em capital cultural mais ampliado que possibilitasse o desenvolvimento de estratégias de escolarização menos funcionais e mais expressivas (com critérios mais pedagógicos e relacionados à qualidade das escolas, por exemplo).

E, por fim, os pais professores Paulo e Jerônimo tinham filhos matriculados tanto na rede pública quanto privada. Na família de Paulo, o primeiro filho cursou integralmente na rede particular as modalidades de ensino educação infantil até anos finais do ensino fundamental, e, no ensino médio, estava cursando uma escola federal, Centro de Educação Tecnológica de Minas Gerais (Cefet), localizada em outra cidade. Podemos identificar, assim, nessa trajetória, a escolarização em escolas consideradas de prestígio, rede particular no ensino fundamental e rede pública federal no Ensino Médio. No caso da segunda filha, estava cursando o $8^{\circ}$ ano na rede particular de ensino. Com relação aos critérios da escolha do estabelecimento de ensino, observamos que essa família dispunha de e utilizava informações “quentes” (VAN ZANTEN, 2010) sobre o sistema de ensino 
para matricular seus filhos nas escolas, adquiridos pela rede de relações sociais, ou seja, pelo capital social (BOURDIEU, 1998), ${ }^{6}$ estabelecido nos relacionamentos com outras famílias. Além disso, os dados da entrevista revelaram que o material didático e a proposta pedagógica da instituição também eram fatores levados em consideração pelos pais.

E, na família de Jerônimo, uma filha estudava na rede estadual de ensino desde o início da escolaridade, diferentemente do filho mais novo, que tinha seu percurso escolar todo realizado em escolas da rede particular de ensino. Quanto aos critérios levados a cabo na escolha da escola pública por esse pai, referiam-se ao fato de o pai professor ter trabalhado em várias instituições públicas. Porém, segundo o relato desse pai, quando matriculou o filho mais novo na rede privada, os pais dialogaram com a filha interrogando-a se queria também optar por uma escola privada ou continuar na rede pública. De acordo com o pai, ela "estava muito bem na escola pública, ela optou por continuar na escola pública. Eu achei ótimo, ela mesma fez opção”. Especificamente quanto aos critérios da escolha da escola particular para o filho, eles foram: "proximidade com, também uma escola que todos falam muito bem, né, mais próxima da nossa casa, né, os primos estão lá juntos e, então, foram esses critérios, mas é uma escola renomada, uma boa escola" (Pai professor Jerônimo). Nesse relato, observamos que, implicitamente, o pai professor mencionou a qualidade de ensino como um critério que auxiliou na escolha da escola para o filho, critério esse que não foi destacado pelos pais professores deste estudo que têm filhos matriculados na rede privada de ensino. Podemos também inferir que, no caso dos pais professores que matricularam seus filhos em escolas privadas, o critério "qualidade da escola” já era algo dado como certo, tendo em vista o maior prestígio das escolas particulares em relação às escolas públicas de um modo geral.

Em resumo, é possível dizer que a escolha dos estabelecimentos de ensino realizada pelos pais professores para escolarizar os filhos está, em certa medida, relacionada às condições materiais e simbólicas de existência. Além disso, os trunfos adquiridos pela profissão docente os tornam capazes de escolher, dentro do universo de possibilidades, a escola que atenda melhor aos seus objetivos. Assim, mesmo nos casos em que os pais professores fizeram escolhas nem sempre reconhecidas como "boas escolhas" e mesmo que os filhos estudassem em escolas nem sempre consideradas de prestígio, de modo geral, os dados indicam que os pais professores investigados exerciam uma escolha ativa no processo de escolarização dos filhos e se utilizavam do “capital de informações” (VAN ZANTEN, 2010) sobre o sistema escolar de que dispunham para realizar escolhas que fomentassem a vida escolar dos filhos, ou que, ao menos, minimizassem possíveis efeitos negativos da escolarização em escolas da rede pública de ensino.

6 Segundo Bourdieu (1998, p. 67), o capital social é a rede de relações sociais de um grupo, ou seja, a vinculação a um determinado grupo que detém propriedades comuns, sendo "unidos por ligações permanentes e úteis". 


\section{DIMENSÕES DO ACOMPANHAMENTO PEDAGÓGICO}

As práticas educativas e de monitoramento na vida escolar dos filhos nas famílias dos pais professores investigados neste estudo, muitas vezes, eram afetadas pelo fator trabalho. Os dados evidenciaram que, nas famílias dos pais professores Sandro, Maurício, Jerônimo, José e João, devido à sobrecarga de trabalho, eles recorriam às esposas, mesmo nos casos em que elas eram menos escolarizadas, para dividirem o acompanhamento das tarefas escolares dos filhos.

Porém, parece claro que, mesmo nesses casos, os pais professores compartilhavam de todo o processo, ainda que fosse nos bastidores. Embora, em algumas famílias, o acompanhamento fosse compartilhado pelos pais e mães, no caso da escolarização nas séries mais avançadas (ensino médio), que demandava um maior conhecimento científico/escolar e pedagógico, era o pai professor que se incumbia do trabalho de acompanhar as lições de casa. E, na família do pai professor Pedro, a tarefa de acompanhamento das atividades escolares era realizada exclusivamente pelo pai professor. Os seus depoimentos indicaram que as informações que o pai professor possuía sobre a escola e os professores orientavam os modos de acompanhamento nas tarefas escolares da filha, e o pai utilizava conhecimentos pedagógicos para exigir que ela fosse acompanhada na escola, pelos professores, em suas dificuldades.

Por sua vez, na família de Henrique, identificamos que o apoio às atividades escolares realizadas no espaço doméstico não era totalmente dividido entre os pais, e concentrava-se mais na figura da mãe. A participação do pai professor ocorria somente nos momentos em que a esposa não compreendia as atividades a serem realizadas. Segundo o pai, a centralidade do apoio da mãe nas atividades escolares era justificada pela maior presença da esposa no espaço domiciliar. A sobrecarga de trabalho também foi apresentada, na pesquisa de Andrade (2006), como um elemento que dificulta o acompanhamento sistemático das mães professoras na escolarização dos filhos. Desse modo, notamos que esse contexto é semelhante em algumas famílias dos pais professores que foram investigados.

Já na família do pai professor Paulo, o apoio ocorria à medida que os filhos tinham dificuldades para executar alguma tarefa. Os filhos recorriam tanto à mãe quanto ao pai, segundo os relatos do pai professor, exceto no tocante à disciplina de Matemática. Nesse caso, era o irmão que auxiliava a filha desse pai professor. Glória (2007) relata que, em sua pesquisa, os irmãos mais novos se beneficiavam dos auxílios de seus irmãos mais velhos, principalmente quando havia um intervalo maior dos nascimentos.

Por fim, na família do pai professor Marcos, o filho estudava em tempo integral e os pais trabalhavam o dia inteiro, sendo que essa situação diferia daquela das demais famílias investigadas, pois o filho não realizava as tarefas escolares no espaço doméstico. O pai professor foi perguntado sobre o modo como acompanhava os deveres de casa, tendo em vista que eram realizados na própria escola. Ele ressaltou que, às vezes, conferia as lições - "de vez em quando, nem sempre" - no entanto, era a esposa que executava essa tarefa: "uma olhadinha de vez em 
quando para ver se está, né, até o material mesmo que..., o que está levando, se está, né: 'Você está esquecendo de alguma coisa', se está faltando alguma coisa”.

Diante disso, em referência ao controle e monitoramento pelos pais professores das atividades realizadas em casa pelos filhos, os dados indicaram que não havia um forte controle e regulamentação das atividades escolares, como foi evidenciado na pesquisa de Nogueira (2011). O acompanhamento desses pais professores na escolarização dos filhos era mais atenuado. Nogueira (2011) demostrou que os pais professores monitoravam regularmente as atividades escolares dos filhos e exerciam um controle mais intenso, denominado pela autora de “corpo a corpo”. No entanto, Nogueira (2011) ressalta que, no grupo de famílias em que as condições objetivas e simbólicas de existência eram menos favoráveis em relação aos outros grupos de professores por ela pesquisados, embora o acompanhamento da escolarização dos filhos estivesse presente nas famílias, notou-se que os pais professores delegavam essa função a outras pessoas (avós, tios, vizinhos). No caso particular desse estudo, observamos que os pais professores recorriam às esposas para dividirem o acompanhamento parental quando os filhos não conseguiam realizar as atividades sozinhos. Sendo assim, parece que esse fenômeno pode estar ligado aos imperativos econômicos das famílias investigadas, pois, impossibilitadas de pagar aulas particulares para os filhos, recorriam às esposas para dividirem ou realizarem esse acompanhamento, uma vez que, na maioria dos casos, os pais professores necessitavam trabalhar em mais de um cargo e, consequentemente, havia uma sobrecarga de trabalho que afetava o modo como os pais professores acompanhavam seus/suas filhos/as no processo educacional.

Ainda nesse contexto, interrogamos os pais professores se os filhos realizavam somente as tarefas que a escola solicitava ou se eles propunham outros tipos de atividades de fomento ao estudo. Nesse quadro, identificamos que, na maioria das famílias investigadas, os filhos desenvolviam somente as tarefas solicitadas pela escola, sendo que os pais relataram que os filhos eram livres para escolherem outras atividades que quisessem realizar, como a leitura de livros, por exemplo. Para o pai professor Maurício, introduzir novas atividades para os seus filhos era bastante oneroso, porque, segundo ele, "não é fácil para a gente introduzir mais atividades tendo cinco filhos para criar; então, é muito difícil, já tem serviço demais da conta”. Essa realidade apresentada pelo pai professor pode estar relacionada ao tamanho dessa família - mais extensa em relação às demais -, às suas condições de vida e à necessidade de trabalhar, que era, também por isso, algo crucial.

Nas famílias de Jerônimo, Sandro e João, identificamos que os filhos realizavam outras atividades, tais como: reforço das atividades escolares em casa; fazer provas de séries mais avançadas; estudo diário em casa (redação, leitura de jornais), reforço preparatório para olimpíadas de matemática organizado pela escola. E, na família do pai professor Paulo, foi relatado que o filho mais velho fez curso preparatório de Física e Química. No que diz respeito às aulas particulares, esse recurso foi utilizado nas famílias de Jerônimo e Paulo. Nesse contexto, 
observamos que os pais professores buscavam estratégias para assegurar o sucesso escolar dos filhos e, por isso, faziam investimentos na escolarização deles característicos das classes médias, como demonstra Nogueira (1995), pois o futuro profissional e escolar dos filhos será garantido por via da escola (BOURDIEU, 2008). E, ainda, o fato de os pais exercerem profissionalmente a docência amplia o conhecimento deles sobre o mundo escolar, o que propiciava que criassem estratégias rentáveis ao processo de formação educacional dos/as filhos/as.

\section{MODOS DE INTERVENÇÃO DOS PAIS PROFESSORES NA ESCOLA DOS FILHOS/AS}

No tocante aos modos de intervenção dos pais professores na instituição escolar por quaisquer queixas ou dificuldades encontradas pela prole na escola, os dados indicam que eram raras as vezes em que os filhos reclamavam de algo para os pais, o que nos fez supor que as coisas vão bem na escola para esses filhos/as. Nos depoimentos dos pais professores Henrique e Sandro, foi declarado que eles não faziam “intervenção direta” (NOGUEIRA, 2011) na escola, sendo que, no primeiro caso, possivelmente, porque os filhos estão indo bem na rede de ensino e não encontraram nenhum problema e, no segundo caso, porque o pai tinha considerado suficiente o acompanhamento em casa, quando priorizava o diálogo com a filha. Talvez isso ocorra pelo fato da esposa do pai professor Sandro trabalhar como professora na mesma escola em que a filha estudava, deixando-o informado de todas as possíveis situações que ocorriam na instituição ou fazendo as possíveis intervenções. Nas famílias de Paulo, Jerônimo e Vicente, quando era necessário aos pais intervirem na escola, a primeira iniciativa era a de dialogar com os filhos para saber o que aconteceu e, em seguida, fazer contato com a instituição escolar, inicialmente com o diretor e depois com os professores. O mecanismo utilizado pelos pais professores para fazer as suas intervenções na escola era o contato telefônico e, quando sentiam mais necessidade de dialogar com a instituição escolar, em alguns casos, o pai professor solicitava com insistência uma reunião com a direção. Já o professor Pedro relatou que era ele mesmo que ia à escola e que o primeiro contato era feito com a professora por meio da agenda.

Por sua vez, os depoimentos do pai professor João indicam que ele fazia uma intervenção mais direta na escola, pois, independentemente de ocorrer um problema ou não com os filhos, sua presença na escola ocorria pelo menos uma vez por mês. O entrevistado declarou que conversava com os professores dos filhos: "e vejo o que está acontecendo, como está sendo o rendimento e, ocasionalmente, se ocorrer, de tiver um pequeno probleminha, eu também vou” (Pai professor João).

Nogueira (2011) também demonstrou que os pais professores entrevistados de sua investigação utilizavam, como estratégia, o "contato direto na escola" para prevenir e sanar as dificuldades encontradas pelos filhos. A pesquisadora discutiu que, no grupo de pais professores que escolarizavam os filhos somente na rede pública de ensino, eles utilizavam diversas estratégias, tais como escolher 
o lugar do filho na turma, o(a) professor(a) do filho, etc., o que evidencia um comportamento denominado, pela autora, de "colonização do estabelecimento público”. Esse comportamento mais incisivo, de modo geral, não foi evidenciado em nosso estudo. Os pais professores participantes de nossa pesquisa desenvolviam estratégias de intervenção na escola bem menos visíveis e diretas, e esse comportamento menos interventor pode estar ligado a um sentimento de pudor, que eles demonstraram em seus relatos, para intervir diretamente na escola, e que, por sua vez, pode estar relacionado às questões de gênero. Isso porque, em um contexto majoritariamente feminino, os pais professores sentiam-se constrangidos ao ter que fazer algum tipo de intervenção mais direta na escola dos filhos e principalmente junto aos colegas de profissão, que, em grande parte, eram professoras. Outra hipótese sugerida é a de que os pais professores, cientes de que os filhos iam bem na escola, ficavam menos preocupados e desenvolviam outras estratégias de acompanhamento parental na escolarização dos filhos no ambiente familiar.

No entanto, nos depoimentos do pai professor Marcos, a intervenção diante de eventuais problemas encontrados pelos filhos na escola diferia daquela das demais famílias pesquisadas, pois, devido ao fato de o filho estudar na mesma escola em que o pai trabalhava, ele sempre se preocupava em separar o papel de pai e de professor no ambiente de trabalho. Ele ressaltou que, quando havia algum problema, evitava conversar diretamente com os professores e recorria ao diretor da escola, "porque tem as outras pessoas que trabalham, mas a responsabilidade de quem que tem..., a responsabilidade maior é o diretor da escola”. Assim, o pai professor relatou certo pudor para intervir diretamente na escola diante de eventuais problemas encontrados pelo filho e talvez seja por isso que, em sua percepção, era necessário um cuidado para que os dois papéis, o de pai e o de professor, fossem mantidos separados. E, ainda, quando intervém na escola, o profissional ao qual o pai professor recorre é o diretor, o que pode evidenciar um afastamento em relação aos/às professores/as dos filhos. Esse fenômeno é diferente no caso das mães professoras investigadas por Nogueira (2011), pois elas mantinham uma relação bem estreita e incisiva com os/as professores/as dos filhos/as.

Com relação à receptividade dos profissionais da escola quando os pais intervinham na instituição na busca de solucionar os problemas encontrados pelos filhos, percebemos que, na maioria dos depoimentos, os pais professores relataram que foram bem recebidos. Além disso, alguns pais professores ponderaram que o fato deles serem conhecidos pela instituição escolar ou terem trabalhado na escola onde o filho estudava facilitava a comunicação. De acordo com Vieira e Relvas (2005), os “conhecimentos vários” adquiridos no exercício da profissão docente impactam positivamente na vida familiar dos pais professores, favorecendo as relações interpessoais. Como vemos neste estudo, impacta positivamente nas relações estabelecidas entre os pais professores e os profissionais da instituição de ensino. É preciso ressaltar, no entanto, que somente o pai professor Paulo relatou que nem sempre havia uma boa receptividade dos profissionais da escola, pois “intervir na escola, muitas vezes, pode fazer com que seja visto como o pai 
chato, pai enjoado, pai eu não sei o quê, entendeu?...”. Nesse sentido, observamos que o pudor demonstrado nos discursos de alguns pais professores entrevistados também foi percebido nos depoimentos do pai professor Paulo. Sendo assim, ele relatou que prefere que a esposa converse com os profissionais da instituição escolar, "porque eu sou daqui da cidade, então, se a gente conhece todo mundo, e a [esposa] é de fora”. Dessa forma, o fato de o pai professor ser conhecido pela comunidade escolar nem sempre facilitava a relação entre eles nos momentos em que fazia intervenções na escola, diferentemente do que ocorria nas demais famílias investigadas.

Ainda nesse quadro de discussão, levantamos outras questões acerca da relação dos pais professores com os professores dos filhos - se eles os procuravam, com que frequência e sobre que tipos de assuntos costumavam conversar. Os pais professores Sandro, Jerônimo, Mauricio, Henrique e Pedro indicaram que eles mantinham uma relação mais distante com os professores dos seus filhos. Se analisarmos os dados da pesquisa de Nogueira (2011), observamos que a maioria dos pais professores entrevistados por ela estabeleciam um contato contínuo com os professores dos filhos e demais profissionais da escola, o que não foi demonstrado com tanta frequência em nosso estudo, pois muitas vezes o contato com os professores dos filhos ocorria somente nas reuniões escolares. Talvez isso se desse porque os pais professores se sentiam constrangidos em procurar os professores dos filhos para dialogar fora do espaço da reunião e temiam ser mal vistos pelos colegas, ou seja, percebidos como pais demasiadamente exigentes.

Por sua vez, em outras cinco famílias dos pais professores José, João, Marcos, Paulo e Vicente, percebemos que eles mantinham uma relação mais próxima com os professores dos filhos, sendo que, nos casos dos pais professores Vicente e Marcos, essa relação era facilitada pelo fato de os pais professores estarem trabalhando na mesma escola em que os filhos estudavam. Os dados indicam que os assuntos eram mais direcionados ao rendimento escolar e ao comportamento dos filhos.

No tocante aos modos de participação das famílias nas atividades realizadas pelas escolas, como, por exemplo, eventos, encontros e reuniões, identificamos, por meio dos depoimentos dos pais professores, que, nos eventos comemorativos promovidos pela escola, a maioria das famílias eram participativas. No entanto, quanto às reuniões, percebemos que a presença era marcada, muitas vezes, somente pela mãe ou pelo pai, devido aos horários de trabalho.

\section{CONSIDERACCÕES FINAIS}

À guisa de conclusão, é possível dizer que, se os estudos nacionais e internacionais demonstraram efeitos positivos na vida familiar de pais professores e seus impactos na escolarização dos filhos - "efeito pai professor” (NOGUEIRA, 2011), essa realidade também foi evidenciada em nosso estudo. Dessa forma, a hipótese que norteava nossa investigação pôde ser confirmada. O fato de ser pai e ser professor modifica o modo de funcionamento da dinâmica interna das famílias, 
bem como a maneira como os pais professores acompanham os/as filhos/as no processo de escolarização e como possibilitam o desenvolvimento de estratégias educativas bastante rentáveis para a vida escolar da prole, pois a bagagem de conhecimentos adquiridos nas experiências e vivências no ambiente escolar interfere positivamente nessas famílias. Porém há de se ressaltar que o efeito pai professor (NOGUEIRA, 2011, 2013), embora tenha sido identificado nas famílias dos pais professores pesquisados, ocorre de maneira diversa e em graus variados. E são justamente essas nuanças que contribuem para ampliar a compreensão sobre a mobilização familiar no quadro da vida escolar dos filhos.

A primeira nuança diz respeito aos modos de funcionamento interno das famílias: parece que ter uma carga extensiva de trabalho aliada às condições socioeconômicas mais restritivas interfere fortemente na organização da vida diária dos pais professores e nas tarefas desenvolvidas no seio familiar, pois a presença deles no espaço doméstico, em muitos casos, é bastante reduzida. Em referência à distribuição das tarefas domésticas, obtivemos como resultado que, na maioria dos casos, embora os pais professores tenham alta escolaridade, no tocante aos cuidados gerais com os filhos, permanece uma tradicional divisão sexual do trabalho doméstico, mesmo em famílias em que as esposas possuem um grau de escolaridade similar àquele dos seus maridos. Assim, os pais professores assumem o papel de "colaboradores" (MARTINS; LUZ; CARVALHO, 2010) no quadro de distribuição das tarefas domésticas, enquanto são as mães as responsáveis por grande parte dessas atribuições.

A segunda nuança se refere ao modo de acompanhamento da escolarização e ao apoio às tarefas escolares. Embora as mães fossem as protagonistas nas tarefas de apoio escolar, os pais professores não se abstinham dessa responsabilidade. Eles faziam o acompanhamento de dois modos: ou ficavam nos bastidores, monitorando a tarefa das mães e entravam "em cena" quando havia uma dificuldade maior apresentada pelos filhos ou, no caso dos filhos matriculados nas séries mais avançados do ensino fundamental ou ensino médio, eles tomavam para si a responsabilidade do acompanhamento. Como uma terceira nuança, temos a escolha da escola pública pelas famílias. Nesse aspecto, diferentemente dos resultados obtidos em outras pesquisas sociológicas e empíricas realizadas com pais professores (SANTANA, 2005; REIS, 2006; NOGUEIRA, 2011), em nossa investigação, seis dos dez pais professores investigados escolarizavam a prole somente na rede pública de ensino, contrariando a lógica do "evitamento da rede pública" (NOGUEIRA, 2011). Dessa forma, os dados coletados indicaram que a predominância da "escolha" da escola pública para matricular os/as filhos/as estava relacionada às condições materiais e simbólicas de existência em que viviam as famílias.

Assim, os pais professores, cientes da inevitabilidade em matricular os/as filhos/as em instituições públicas, buscavam outras estratégias rentáveis no processo de escolarização a fim de reduzir os possíveis efeitos negativos advindos de uma formação em escolas públicas (NOGUEIRA, 2011). Os depoimentos indicaram que a maioria dos pais professores que tinham filhos matriculados somente na rede pública eram os que desenvolviam estratégias de antecipação e 
compensação, tais como: acompanhamento forte na escolarização dos filhos em casa, antecipação do processo de alfabetização, incentivo à leitura, antecipação dos conteúdos programados no currículo (fazer provas de séries mais avançadas), realização de atividades escolares extras em casa. Sendo assim, a necessidade de escolarizar o filho na rede pública os impulsionava a desenvolver outras estratégias que "compensassem", de certo modo, essa inevitabilidade.

Outra nuança a ser destacada refere-se ao monitoramento e ao controle das tarefas escolares dos filhos. Observamos que os pais professores não exerciam um "corpo a corpo", ou seja, um acompanhamento mais intenso das atividades escolares e extraescolares desenvolvidas pelos/as filhos/as, como demonstrou Nogueira (2011). Os pais professores investigados acompanhavam a vida escolar de seus filhos de modo menos direto, pois dividiam essas tarefas de apoio com as esposas, porque, acometidos por condições simbólicas e econômicas desfavoráveis, e necessitando trabalhar com carga horária extensiva para melhorar as condições de vida da família, tinham menos tempo e condições objetivas para acompanhar de perto as atividades escolares dos filhos. Mas isso não significa que havia algum tipo de omissão ou de distanciamento por parte desses pais; ao contrário, eles estavam sempre "por perto" e atentos, dando o suporte necessário às mães e também aos filhos no acompanhamento da vida escolar.

Por fim, no tocante aos modos de intervenção dos pais professores nos estabelecimentos de ensino frequentados pelos filhos, constatamos, por meio dos discursos, que as intervenções diretas eram raras e, quando aconteciam, tinham o objetivo de solucionar problemas mais graves encontrados pelos/as filhos/as. Desse modo, quando necessitavam fazer intervenções, na maioria das famílias, os pais professores primeiramente faziam o contato com o diretor da escola e não diretamente com os professores dos filhos. Os pais professores mantinham uma relação mais distante com os professores dos filhos, demonstrando, assim, um sentimento de pudor e de constrangimento ao se relacionarem com os profissionais que ministravam aulas para os filhos. Na tentativa de compreender esse comportamento, levantamos duas possíveis explicações que podem estar imbricadas: primeiramente, talvez a fraca intervenção ocorra porque os pais professores estão conscientes de que seus filhos estão bem na escola e obtêm um bom desempenho escolar, o que dispensa maiores contatos com a instituição; em segundo lugar, intervir na escola e manter uma relação mais estreita e contínua com os professores dos filhos parece ser constrangedor para alguns pais professores porque são homens em um contexto profissional bastante feminino.

Para finalizar, é possível argumentar que, para compreendermos as práticas educativas dos pais professores, é preciso levar em consideração a condição de vida em que viviam essas famílias, pois fica evidente que os recursos simbólicos e econômicos detidos parecem interferir fortemente no acompanhamento dos pais professores na escolarização dos/as filhos/as. 


\section{REFERÊNCIAS}

ANDRADE, Joelma Marçal de. Profissão docente e escolarização dos filhos. 2006. 122 f. Dissertação (Mestrado em Educação) - Programa de Pós-graduação em Educação, Centro de Ciências da Educação, Universidade Federal de Santa Catarina, Florianópolis, 2006.

ASSOCIAÇÃO BRASILEIRA DE EMPRESA DE PESQUISA - ABEP. Critério Brasil 2015 e atualização da distribuição de classes para 2016, São Paulo: ABEP, 2016. Disponível em: http://www.abep.org/criterio-brasil.

BARG, Katherin. The school success of teacher children. In: COLLOQUE FABRICATION FAMILIALE DE LA RÉUSSITE SCOLAIRE D’AJUSTEMENT AUX PUBLICS. Annales [...] Paris: Université Paris-Dauphine, 2011. p. 1-17.

BOURDIEU, Pierre. O capital social: notas provisórias. In: NOGUEIRA, Maria Alice; CATANI, Afrânio (org.). Escritos de Educação. Petrópolis: Vozes, 1998. p. 65-69.

BOURDIEU, Pierre. A distinção: crítica social do julgamento. Porto Alegre: Zouk, 2008.

BRASIL. Instituto Nacional de Estudos e Pesquisas Educacionais Anísio Teixeira. Estudo exploratório sobre o professor brasileiro com base nos resultados do Censo Escolar da Educação Básica 2007. Brasília: Inep, 2009.

GLÓRIA, Dília Maria da. Uma análise de fatores sociodemográficos e sua relação com a escolarização dos filhos em famílias de camadas médias. 2007. 288 f. Tese (Doutorado em Educação) - Universidade Federal de Minas Gerais, Belo Horizonte, 2007.

GOLDANI, Ana Maria. As famílias brasileiras: mudanças e perspectivas. Cadernos de Pesquisa, Fundação Carlos Chagas, n. 91, p. 7-22, 1994.

INSTITUTO BRASILEIRO DE GEOGRAFIA E ESTATÍSTICA. Síntese de indicadores sociais: uma análise das condições de vida da população brasileira. Rio de Janeiro: IBGE, 2016.

LASNE, Annie da Costa. La singulière réussite scolaire des enfants d'enseignants: des pratiques éducatives parentales spécifiques? 2012. 384 f. Thèse (Doctorat en Education) - Université de Bourgogne, France, 2012.

MARTINS, Conceição Garcia; LUZ, Nanci Stancki da; CARVALHO, Marília Gomes de. Relações de gênero no trabalho doméstico. In: FAZENDO GÊNERO, DIÁSPORAS, DIVERSIDADES, DESLOCAMENTOS, 9, Santa Catarina, Anais [...], p. 1-10, 23 a 26 de agosto de 2010.

NOGUEIRA, Maria Alice. Famílias de camadas médias e a escola: bases preliminares para um objeto em construção. Educação e Realidade, v. 20, n. 1, p. 9-25, jan./jun. 1995.

NOGUEIRA, Marlice de Oliveira e. Pais professores e a escolarização dos filhos. 2011. 267 f. Tese (Doutorado em Educação) - Universidade Federal de Minas Gerais, Belo Horizonte, 2011.

NOGUEIRA, Marlice de Oliveira e. Efeito pai professor: o impacto da profissão docente na vida escolar dos filhos. Revista Brasileira de Educação, v. 18, n. 52, p. 65-79, 2013.

NOGUEIRA, Marlice de Oliveira e. Bom aluno, bom filho: a tensão entre a construção de si e o sucesso escolar em famílias de pais professores. Revista de Educação, Campinas, v. 20, n. 2, p. 67-79, maio/ago. 2015.

NOGUEIRA, Marlice de Oliveira e; NOGUEIRA, Maria Alice. Quando os professores escolarizam os filhos na rede pública de ensino: da inevitabilidade à colonização. Educação em Revista, Belo Horizonte, n. 33, p. 1-26, 2017.

RESENDE, Tânia de Freitas; NOGUEIRA, Claudio Marques; NOGUEIRA, Maria Alice. Escolha do estabelecimento de ensino e perfis familiares: uma faceta a mais das desigualdades escolares. Educação e Sociedade, Campinas, v. 32, n. 117, p. 953-970, out./dez. 2011.

REIS, Rosemeire. Os professores da escola pública e a educação escolar de seus filhos: uma contribuição ao estudo da profissão docente. São Paulo: Paulinas, 2006. 255 p. 
SANTANA, Regina Palma A. de. Professor da escola pública: onde estuda seu filho? A família do professor na escolha da escola dos filhos. 2005. 127 f. Dissertação (Mestrado) - Universidade Católica de Salvador, Salvador, 2005.

SILVA, Rosemeire Reis da. Os professores da escola pública e a educação escolar de seus filhos: uma contribuição ao estudo da profissão docente. In: ASSOCIAÇÃO NACIONAL DE PÓS-GRADUAÇÃO E PESQUISA EM EDUCAÇÃO, 25, 2002, Caxambu, Anais [...], 2002.

SILVA, Pedro. Escola-família: uma relação armadilhada - interculturalidade e relações de poder. Porto: Profedições, 2003. 412 p.

SINGLY, François de. Sociologia da família contemporânea. Trad. Clarice Ehlers Peixoto. Rio de Janeiro: Editora FGV, 2007. 208 p.

VAN ZANTEN, Agnès. A escolha dos outros: julgamentos, estratégias e segregações escolares. Educação em Revista, Belo Horizonte, v. 26, n. 3, p. 409-434, dez. 2010.

VIEIRA, Cristina Rocha; RELVAS, Ana Paula. A(s) vida(s) do professor. Lisboa: Quarteto, 2005, v. 4. 203 p.

NOTA: Este artigo é um desdobramento da pesquisa de mestrado de Rosilane Kátia de Oliveira, orientada por Marlice de Oliveira e Nogueira, na Universidade Federal de Ouro Preto. As duas autoras participaram da elaboração e redação de todas as partes do artigo.

AGRADECIMENTO: A pesquisa contou com o apoio financeiro da Universidade Federal de Ouro Preto.

\section{COMO CITAR ESTE ARTIGO}

OLIVEIRA, Rosilane Katia de; NOGUEIRA, Marlice de Oliveira e. Pais professores homens e o acompanhamento da vida escolar dos filhos. Cadernos de Pesquisa, São Paulo, v. 49, n. 174, p. 182-203, out./dez. 2019. https://doi.org/10.1590/198053146641 